\title{
Indirect Model Predictive Control Strategy with Active Damping Implementation for a Direct Matrix Converter Operating at Fixed Switching Frequency
}

\author{
M. Rivera \\ Faculty of Engineering \\ Universidad de Talca, Curicó, Chile \\ marcoriv@utalca.cl
}

\author{
H. Dan \\ School of Information Science and Engineering \\ Central South University, ChangSha, China \\ danie1698@sina.cn
}

\author{
L. Tarisciotti, P. Wheeler \\ Dep. of Electrical and Electronic Engineering \\ University of Nottingham, Nottingham, UK \\ pat.wheeler@nottingham.ac.uk
}

\begin{abstract}
One of the main drawbacks of the implementation of predictive control in a direct matrix converter is the high computational cost and the adequate selection of weighting factors in order to control both input and output sides. In this paper is proposed an indirect model predictive current control strategy enhanced with a fixed switching predictive strategy and an active damping implementation. With all this, the idea is to reduce the computational cost while eliminating the necessity of weighting factors and improving the performance of the full system. The proposed method is based on the fictitious $d c$-link concept, which has been used in the past for the classical modulation and control techniques of the direct matrix converter. Simulated results confirm the feasibility of the proposal demonstrating that it is an alternative method to classical predictive control strategies for the direct matrix converter.
\end{abstract}

Index Terms-active damping, current control, matrix converters, indirect model predictive control, fictitious $d c$-link.

\section{NOMENCLATURE}

$\mathbf{i}_{\mathrm{s}} \quad$ Source current

$\mathbf{v}_{\mathbf{s}} \quad$ Source voltage

$\mathbf{i}_{\mathbf{i}} \quad$ Input current

$\mathbf{v}_{\mathbf{i}} \quad$ Input voltage

$i_{d c} \quad$ Fictitious $d c$-link current

$v_{d c} \quad$ Fictitious $d c$-link voltage

$\mathbf{i}_{\mathbf{o}} \quad$ Load current

$\mathbf{v}_{\mathbf{o}} \quad$ Load voltage

i* $^{*} \quad$ Load current reference

$C_{f} \quad$ Input filter capacitor

$L_{f} \quad$ Input filter inductor

$R_{f} \quad$ Input filter resistor

$R \quad$ Load resistance

$L \quad$ Load inductance

\section{INTRODUCTION}

The direct matrix converter (DMC) can generates sinusoidal input and output currents but also it has regeneration capability and adjustable input displacement power factor [1], [2]. Compared to the back-to-back converter, the DMC features some advantages in terms of power densities and capacity to work in harsh pressures and temperatures. Venturini is one of the most classical modulation techniques together with Pulse Width Modulation (PWM), Space Vector Modulation (SVM) as well as Direct Torque Control (DTC) and Model Predictive
Control (MPC) [2]. MPC utilizes the mathematical model of the system to predict for each valid switching state of the converter the performance of the variables to be controlled at every sampling time. By minimizing a defined cost function, the optimal switching state is selected to be applied in the next sampling instant. There are several issues that still need some attention despite the progress of MPC. When several control objectives are considered in the controller it is necessary the correct selection of weighting factors and this issue is very important because it has a significant consequence on the system behaviour. Generally, the selection is done by using empirical techniques but it is possible to find some papers which present some ideas for the optimal weighting factor selection [3]-[7] although, most of them are complex solutions and require high computation cost. Another issue is the variable switching frequency presents in the classical MPC that produce high ripple in the controlled variables, damaging the system performance specially when the average switching frequency is close to the resonance frequency of the input filter. This issue has been topic for research and now it is possible to find several solutions in the literature. One of the most famous strategy is modulated MPC (M2PC) where the cost function is used for the adequate selection of adjacent vectors and duty cycles in one sampling instant to be applied in the next period to the converter. The concept consists in to use MPC to emulate SVM [8], [9]. With this technique, it is possible to maintain the characteristics of traditional MPC methods such as multi objective control, fast dynamic response, simple inclusion of nonlinearities and constrains but ensuring a fixed switching operation, mitigating the ripple of the controlled variables and improving the system behaviour. An hybrid combination between MPC and SVM allows the operation at fixed switching frequency but also the use of all the available switching states of the DMC (27 valid switching states), which is not possible in the traditional SVM technique where only the fixed vectors are considered [10]. The mitigation of filter resonances when controlled with MPC has also been focus of several publications such as reported in [11]-[13], where the method consists of emulating a damping resistor placed in parallel with the filter capacitor such that the harmonic currents caused by the resonances flow through this resistor. 
To solve issues such as computational cost, weighting factor selections, operation at variable switching frequency and resonances on the input filter, this paper proposes an indirect model predictive control (IMPC) strategy working at fixed switching frequency with active damping implementation. The idea is to emulate the DMC as a two stage converter linked by a fictitious $d c$-link allowing a separated and parallel control of both input and output stages, avoiding the use of weighting factors and choosing into the cost function a set of optimal vectors and their respective duty cycles to be applied to the converter.

\section{Mathematical Model of the DMC}

The general structure of the three-phase DMC is shown in Fig. 1. In order to ensure the safe operation of the DMC, the following expression must be accomplished:

$$
S_{A y}+S_{B y}+S_{C y}=1, \quad \forall y=a, b, c
$$

The relations between the input and output variables of the DMC are defined by:

$$
\begin{gathered}
\mathbf{v}_{\mathbf{o}}=\mathbf{T} \mathbf{v}_{\mathbf{i}} \\
\mathbf{i}_{\mathbf{i}}=\mathbf{T}^{T} \mathbf{i}_{\mathbf{o}}
\end{gathered}
$$

where $\mathbf{T}$ is the instantaneous transfer matrix defined as:

$$
\mathbf{T}=\left[\begin{array}{lll}
S_{A a} & S_{B a} & S_{C a} \\
S_{A b} & S_{B b} & S_{C b} \\
S_{A c} & S_{B c} & S_{C c}
\end{array}\right]
$$

There are some techniques that uses the concept of fictitious $d c$-link in order to simplify the modulation and control of the DMC [14], [15], which consists in to divide the converter into a rectifier and an inverter linked by a fictitious $d c$-link such as represented in Fig. 2. The rectifier have associated six active current space vectors which are represented in Fig. 3 (left) and Table I. The inverter have associated eight voltage space vectors which are represented in Fig. 3 (right) and Table II. The technique modulates both converters separately, but considering the relationship between both stages.

\section{Proposed Method For the DMC}

M2PC has been implemented in a DMC feeding an induction machine [16], [17], where input and output sides of the converter are controlled all together by including a predictive model of the instantaneous reactive input power and a predictive model of the load currents. These predictions are compared with their respective references in a single cost function, being necessary the inclusion of a weighting factor in order to provide more priority to one of the controlled variables. At every sampling period three active and three zero optimal vectors are chosen which are applied to the converter. In this method two main issues are observed: first, it is necessary the adequate selection of a suitable weighting factor value in order to prioritise for the control of the load current or the instantaneous reactive input power and second, as the full converter control is considered, a large amount of available switching states is considered.

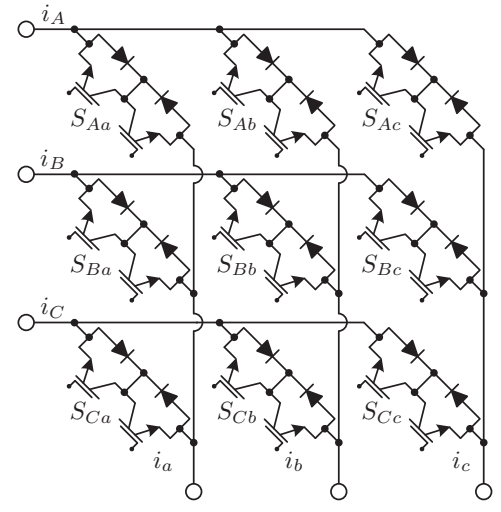

Fig. 1. Power circuit of the direct matrix converter.

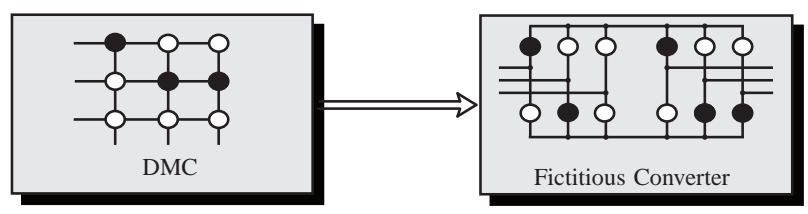

Fig. 2. Representation of the fictitious $d c$-link concept for the DMC.
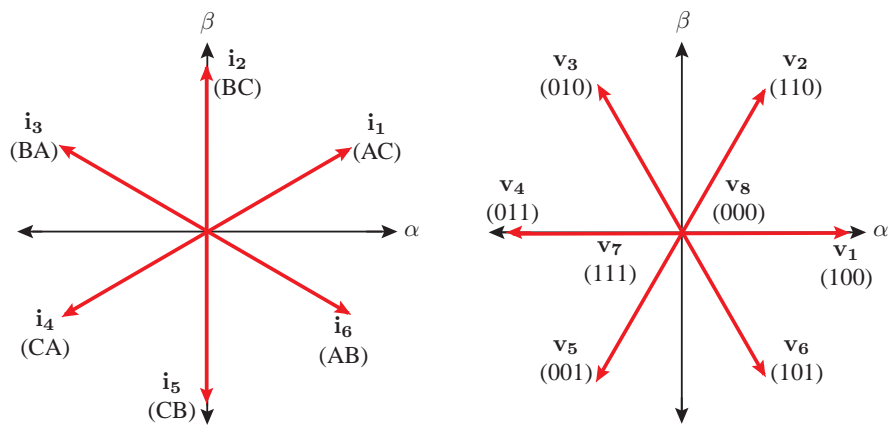

Fig. 3. Current and voltage space vectors of the fictitious converter. Left: current space vectors for the fictitious rectifier, right: voltage space vectors for the fictitious inverter.

TABLE I

VALID SWITCHING STATE ON THE FICTITIOUS RECTIFIER

\begin{tabular}{c|cccccc|ccc|c}
$\#$ & $S_{r 1}$ & $S_{r 2}$ & $S_{r 3}$ & $S_{r 4}$ & $S_{r 5}$ & $S_{r 6}$ & $i_{A}$ & $i_{B}$ & $i_{C}$ & $v_{d c}$ \\
\hline \hline 1 & 1 & 1 & 0 & 0 & 0 & 0 & $i_{d c}$ & 0 & $-i_{d c}$ & $v_{A C}$ \\
2 & 0 & 1 & 1 & 0 & 0 & 0 & 0 & $i_{d c}$ & $-i_{d c}$ & $v_{B C}$ \\
3 & 0 & 0 & 1 & 1 & 0 & 0 & $-i_{d c}$ & $i_{d c}$ & 0 & $-v_{A B}$ \\
4 & 0 & 0 & 0 & 1 & 1 & 0 & $-i_{d c}$ & 0 & $i_{d c}$ & $-v_{A C}$ \\
5 & 0 & 0 & 0 & 0 & 1 & 1 & 0 & $-i_{d c}$ & $i_{d c}$ & $-v_{B C}$ \\
6 & 1 & 0 & 0 & 0 & 0 & 1 & $i_{d c}$ & $-i_{d c}$ & 0 & $v_{A B}$
\end{tabular}

TABLE II

VALID SWITCHING STATE ON THE FICTITIOUS INVERTER

\begin{tabular}{c|cccccc|ccc|c}
$\#$ & $S_{i 1}$ & $S_{i 2}$ & $S_{i 3}$ & $S_{i 4}$ & $S_{i 5}$ & $S_{i 6}$ & $v_{a b}$ & $v_{b c}$ & $v_{c a}$ & $i_{d c}$ \\
\hline \hline 1 & 1 & 1 & 0 & 0 & 0 & 1 & $v_{d c}$ & 0 & $-v_{d c}$ & $i_{a}$ \\
2 & 1 & 1 & 1 & 0 & 0 & 0 & 0 & $v_{d c}$ & $-v_{d c}$ & $i_{a}+i_{b}$ \\
3 & 0 & 1 & 1 & 1 & 0 & 0 & $-v_{d c}$ & $v_{d c}$ & 0 & $i_{b}$ \\
4 & 0 & 0 & 1 & 1 & 1 & 0 & $-v_{d c}$ & 0 & $v_{d c}$ & $i_{b}+i_{c}$ \\
5 & 0 & 0 & 0 & 1 & 1 & 1 & 0 & $-v_{d c}$ & $v_{d c}$ & $i_{c}$ \\
6 & 1 & 0 & 0 & 0 & 1 & 1 & $v_{d c}$ & $-v_{d c}$ & 0 & $i_{a}+i_{c}$ \\
7 & 1 & 0 & 1 & 0 & 1 & 0 & 0 & 0 & 0 & 0 \\
8 & 0 & 1 & 0 & 1 & 0 & 1 & 0 & 0 & 0 & 0
\end{tabular}


To solve these issues, in this paper we use the concept of fictitious $d c$-link in order to propose the IMPC strategy for the DMC. The idea is to separate the control of both input and output fictitious stages of the converter in order to avoid complex and large calculations and as well simplify the controller while avoiding the use of weighting factors. In addition, the proposal enhances the performance of the system by the implementation of active damping method in order to mitigate the resonance of the input filter.

\section{A. Control of the Rectifier}

As indicated in Fig. 3 (left) and Table I, there are six active current space vectors which correspond to the suitable switching states of the rectifier. The proposed technique detailed in Fig. 4, consists in to control the input side of the converter by considering these available switching states and the mathematical model of the rectifier defined by:

$$
\begin{aligned}
& v_{d c}=\left[\begin{array}{lll}
S_{r 1}-S_{r 4} & S_{r 3}-S_{r 6} & S_{r 5}-S_{r 2}
\end{array}\right] \mathbf{v}_{\mathbf{i}} \\
& \mathbf{i}_{\mathbf{i}}=\left[\begin{array}{c}
S_{r 1}-S_{r 4} \\
S_{r 3}-S_{r 6} \\
S_{r 5}-S_{r 2}
\end{array}\right] i_{d c}
\end{aligned}
$$

For the control of the input side it is necessary the prediction model of the source current which is given by the linear model of the input side as:

$$
\begin{gathered}
\frac{d \mathbf{i}_{\mathbf{s}}}{d t}=\frac{1}{L_{f}}\left(\mathbf{v}_{\mathbf{s}}-\mathbf{v}_{\mathbf{i}}\right)-\frac{R_{f}}{L_{f}} \mathbf{i}_{\mathbf{s}} \\
\frac{d \mathbf{v}_{\mathbf{i}}}{d t}=\frac{1}{C_{f}}\left(\mathbf{i}_{\mathbf{s}}-\mathbf{i}_{\mathbf{i}}\right)
\end{gathered}
$$

By considering the guidelines presented in [18] for the current and voltage predictions, it is possible to define the cost function $g_{r}$ associated to the input control in the $\alpha-\beta$ plane:

$$
g_{r}=\left[v_{s \alpha}(k+1) i_{s \beta}(k+1)-v_{s \beta}(k+1) i_{s \alpha}(k+1)\right]^{2}
$$

At every sampling instant $T_{s}$, each pair of current vectors are evaluated for cost function $g_{r}$ which means that for each sector two cost functions are given, the first associated to one current vector $g_{r 1}$ and other related to the adjacent current vector $g_{r 2}$. Later, these cost functions are used to compute the duty cycles which are calculated assuming that they are proportional to the inverse of the corresponding cost function value, where $K_{r}$ is a constant to be determined:

$$
\begin{aligned}
& d_{r 1}=K_{r} / g_{r 1} \\
& d_{r 2}=K_{r} / g_{r 2} \\
& d_{r 1}+d_{r 2}=1
\end{aligned}
$$

With these duty cycles and cost function values, is defined a new cost function which is given by:

$$
g_{r e c}=d_{r 1} g_{r 1}+d_{r 2} g_{r 2}
$$

This is done, at every sampling time, for each of the six sectors and finally, the pair of vectors that minimizes the cost function $g_{r e c}$ are selected as the optimal $\mathbf{v}_{\mathbf{r}}{ }^{o p t}$ to be applied in

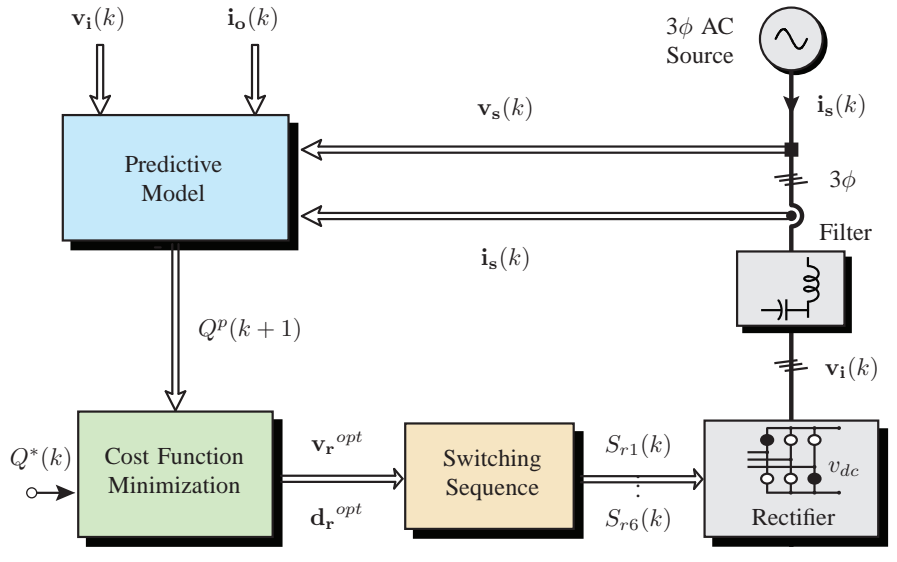

Fig. 4. Indirect predictive control strategy for the fictitious rectifier.

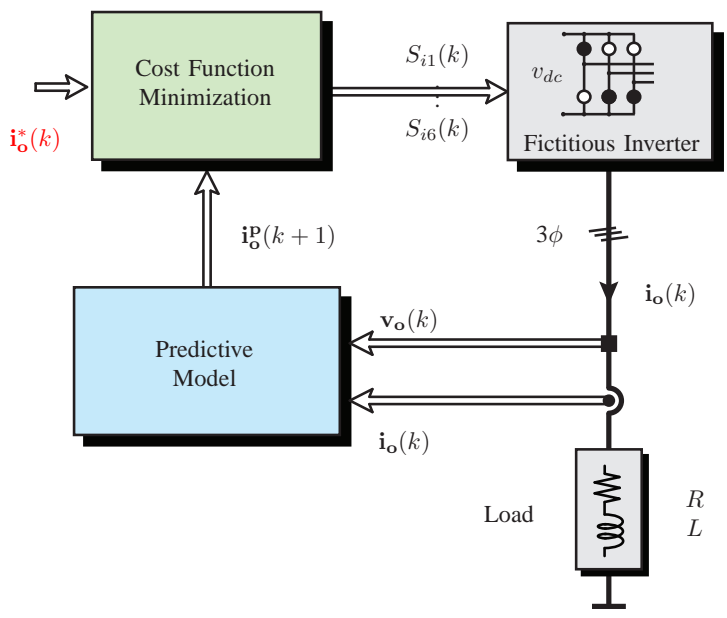

Fig. 5. Indirect predictive control strategy for the fictitious inverter.

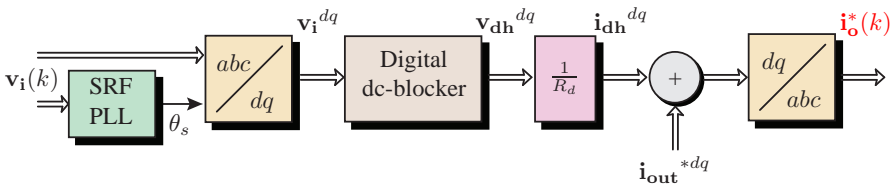

Fig. 6. Active damping implementation.

the next period. The time that each vector is applied is given by:

$$
\begin{aligned}
& t_{r 1}=d_{r 1} T_{s} \\
& t_{r 2}=d_{r 2} T_{s}
\end{aligned}
$$

\section{B. Control of the Inverter}

The control diagram of this stage is represented in Fig. 5. The mathematical model of the inverter is defined as:

$$
\begin{aligned}
& i_{d c}=\left[\begin{array}{lll}
S_{i 1} & S_{i 3} & S_{i 5}
\end{array}\right] \mathbf{i}_{\mathbf{o}} \\
& \mathbf{v}_{\mathbf{o}}=\left[\begin{array}{c}
S_{i 1}-S_{i 4} \\
S_{i 3}-S_{i 6} \\
S_{i 5}-S_{i 2}
\end{array}\right] v_{d c}
\end{aligned}
$$


Assuming a passive $R L$ load, the mathematical model of the load is defined as:

$$
\mathbf{v}_{\mathbf{o}}=L \frac{d \mathbf{i}_{\mathbf{o}}}{d t}+R \mathbf{i}_{\mathbf{o}}
$$

With these definitions, the prediction model of the output side using a forward Euler approximation in eq. (15) is:

$$
\mathbf{i}_{\mathbf{o}}(k+1)=c_{1} \mathbf{v}_{\mathbf{o}}(k)+c_{2} \mathbf{i}_{\mathbf{o}}(k)
$$

where, $c_{1}=T_{s} / L$ and $c_{2}=1-R T_{s} / L$, are constants dependent on load parameters and the sampling time $T_{s}$. The associated cost function $g_{i}$ for the output stage is:

$$
g_{i}=\left[i_{\alpha}^{*}-i_{\alpha}(k+1)\right]^{2}+\left[i_{\beta}^{*}-i_{\beta}(k+1)\right]^{2}
$$

In order to enhance the performance of the system and to mitigate the potential resonance of the input filter excited by potential harmonics in the $a c$ source and the converter itself, in this paper we add an active damping technique to the predictive controller of the inverter, by modifying the load current reference as shown in Fig. 6 and indicated in [12], [13]. In this method, we use a virtual harmonic resistive damper $R_{d}$, which is immune to system parameter variations, in parallel with the input filter capacitors $C_{f}$, to suppress the system harmonics without affecting the fundamental component. The converter draws a damping current proportional to the capacitor voltage, which is extracted by the converter itself, emulating the damping resistance $R_{d}$ as indicated by:

$$
i_{d}=\frac{\mathbf{v}_{\mathbf{i}}}{R_{d}}
$$

This method is easy to implement, do not affects the efficiency of the converter and do not involves additional measurements or any modification to the predictive algorithm.

From Fig. 3 (right), six sectors are identified which are given by two active voltage vectors. At every sampling instant $T_{s}$, each pair of voltage vectors and one zero vector are evaluated for cost function $g_{i}$ which means that for each sector three cost functions are given $g_{i 0}, g_{i 1}$ and $g_{i 2}$. Later, these cost functions are used to compute the duty cycles which are calculated assuming that they are proportional to the inverse of the corresponding cost function value, where $K_{i}$ is a constant to be determined:

$$
\begin{gathered}
d_{i 0}=K_{i} / g_{i 0} \\
d_{i 1}=K_{i} / g_{i 1} \\
d_{i 2}=K_{i} / g_{i 2} \\
d_{i 0}+d_{i 1}+d_{i 2}=1
\end{gathered}
$$

With these duty cycles and cost function values, is defined a new cost function which is given by:

$$
g_{i n v}=d_{i 1} g_{i 1}+d_{i 2} g_{i 2}
$$

This is done, at every sampling time, for each of the six sectors. The pair of vectors that minimizes the cost function $g_{\text {inv }}$ are selected as the optimal $\mathbf{v}_{\mathbf{i}}^{\text {opt }}$ to be applied in the next period. The time that each vector is applied is given by:

$$
\begin{aligned}
t_{i 0} & =d_{i 0} T_{s} \\
t_{i 1} & =d_{i 1} T_{s} \\
t_{i 2} & =d_{i 2} T_{s}
\end{aligned}
$$

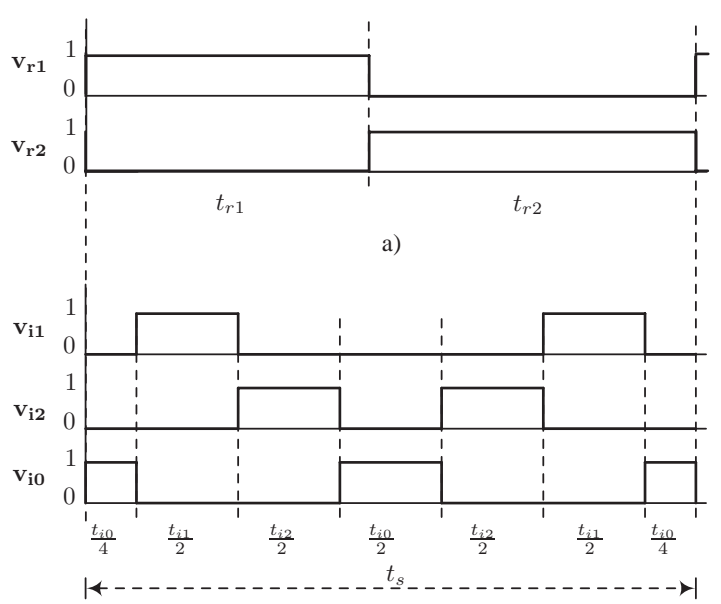

b)

Fig. 7. Switching pattern: a) for the rectifier side; b) for the inverter side.

After obtaining the duty cycles and selecting the optimal vectors to be applied in both the rectifier and inverter, a switching pattern procedure is adopted with the goal of applying the optimal vectors [19] (Fig. 7).

\section{Relationship between the fictitious converter and the DMC}

As it is necessary to apply the switching signals to the switches of the DMC, it is required to adapt the switching states of both input and output fictitious stages to the real one. As indicated in eq. (2), the relationship between the input voltage $\mathbf{v}_{\mathbf{i}}$ and load voltage $\mathbf{v}_{\mathbf{o}}$ depends on the state of the switching given by matrix T. Based on the fictitious definition, the load voltage $\mathbf{v}_{\mathbf{o}}$ is given as indicated in eq. (14). At the same time, the fictitious $d c$-link voltage $v_{d c}$ is given by eq. (5). In summary,

$\mathbf{v}_{\mathbf{o}}=\left[\begin{array}{c}S_{i 1}-S_{i 4} \\ S_{i 3}-S_{i 6} \\ S_{i 5}-S_{i 2}\end{array}\right]\left[\begin{array}{lll}S_{r 1}-S_{r 4} & S_{r 3}-S_{r 6} & S_{r 5}-S_{r 2}\end{array}\right] \mathbf{v}_{\mathbf{i}}$

and thus the relationship between the switches of the DMC and fictitious converter is given as:

$$
\left[\begin{array}{c}
S_{A a} \\
S_{B a} \\
S_{C a} \\
S_{A b} \\
S_{B b} \\
S_{C b} \\
S_{A c} \\
S_{B c} \\
S_{C c}
\end{array}\right]=\left[\begin{array}{c}
\left(S_{i 1}-S_{i 4}\right)\left(S_{r 1}-S_{r 4}\right) \\
\left(S_{i 1}-S_{i 4}\right)\left(S_{r 3}-S_{r 6}\right) \\
\left(S_{i 1}-S_{i 4}\right)\left(S_{r 5}-S_{r 2}\right) \\
\left(S_{i 3}-S_{i 6}\right)\left(S_{r 1}-S_{r 4}\right) \\
\left(S_{i 3}-S_{i 6}\right)\left(S_{r 3}-S_{r 6}\right) \\
\left(S_{i 3}-S_{i 6}\right)\left(S_{r 5}-S_{r 2}\right) \\
\left(S_{i 5}-S_{i 2}\right)\left(S_{r 1}-S_{r 4}\right) \\
\left(S_{i 5}-S_{i 2}\right)\left(S_{r 3}-S_{r 6}\right) \\
\left(S_{i 5}-S_{i 2}\right)\left(S_{r 5}-S_{r 2}\right)
\end{array}\right]
$$

\section{RESULTS}

To validate the effectiveness of the proposed method, simulation results in Matlab-Simulink were carried out considering $C_{f}=21[\mu \mathrm{F}], L_{f}=400[\mu \mathrm{H}], R_{f}=0.5[\Omega], R=10[\Omega], L=10$ $[\mu \mathrm{H}], T_{s}=40[\mu \mathrm{s}]$ and a simulation step of $1[\mu \mathrm{s}]$. 
(a)

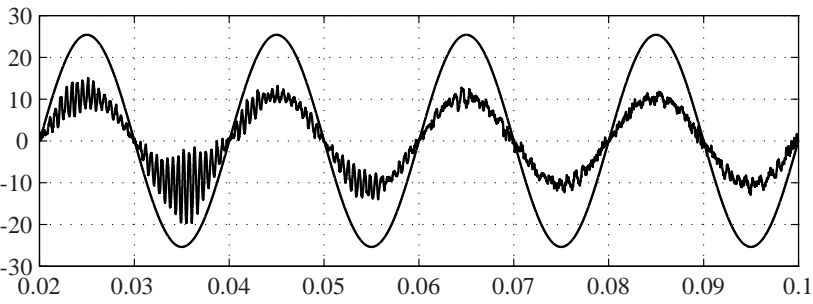

(b)

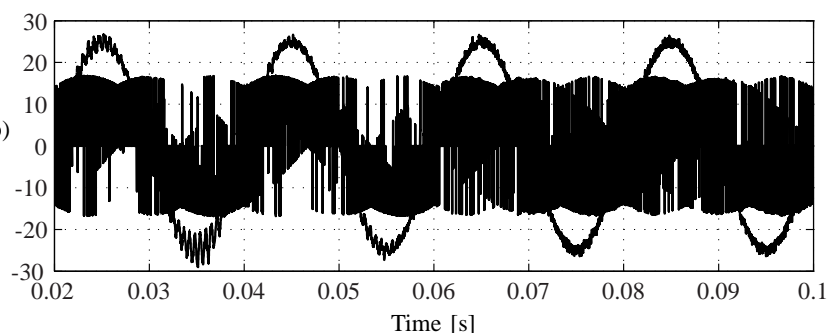

Fig. 8. Simulation results of the classical MPC; before $t=0.06$ [s] without active damping, after $t=0.06$ [s] with active damping: (a) source voltage $v_{s A}[\mathrm{~V} / 10]$ and source current $i_{s A}[\mathrm{~A}]$; (b) capacitor voltage $v_{A}[\mathrm{~V} / 10]$ and input current $i_{A}[\mathrm{~A}]$.

(a)
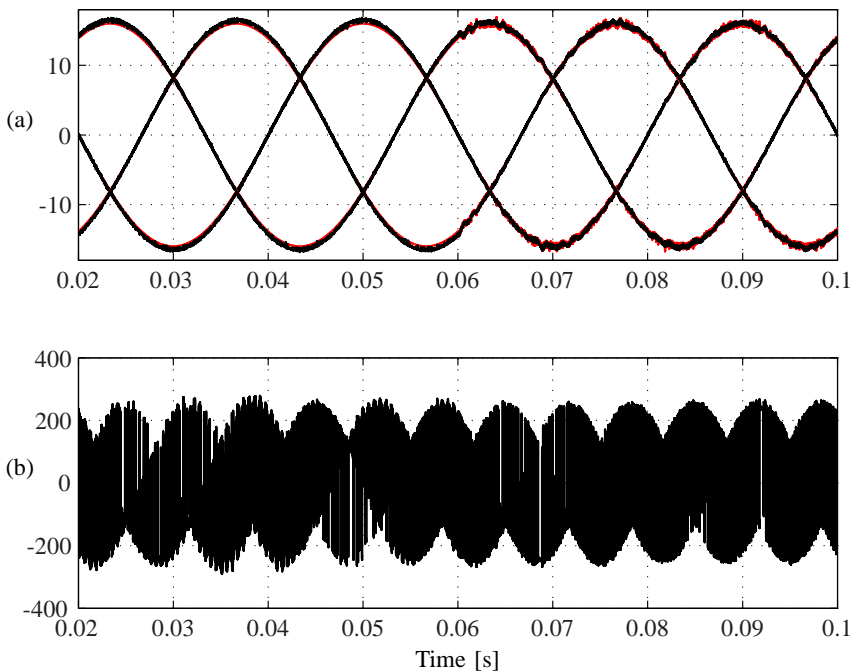

Fig. 9. Simulation results of the classical MPC; before $t=0.06$ [s] without active damping, after $t=0.06$ [s] with active damping: (a) load currents $\mathbf{i}_{\mathbf{o}}$ [A] and its respective references $\mathbf{i}_{\mathrm{o}}{ }^{*}[\mathrm{~A}]$; (b) load voltage $v_{a}[\mathrm{~V}]$.

In this paper two cases are presented. First the classical MPC with and without active damping implementation is presented followed by the proposal with and without active damping technique.

Fig. 8 and Fig. 9 show simulated results for the classical MPC technique for the DMC with and without active damping implementation. Before the implementation of active damping technique, Fig. 8(a) shows the source voltage $v_{s A}$ and source current $i_{s A}$ which is in phase to its respective voltage but as expected and due to the variable switching frequency it presents several oscillations and distortions with a THD of $66.95 \%$. This resonance is also reflected in the capacitor voltage $v_{A}$ shown in Fig. 8(b). (a)

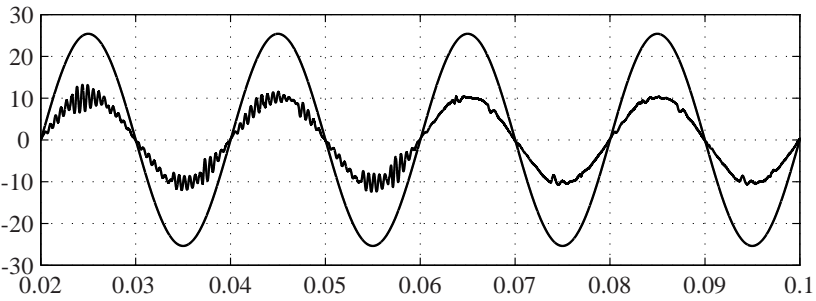

(b)

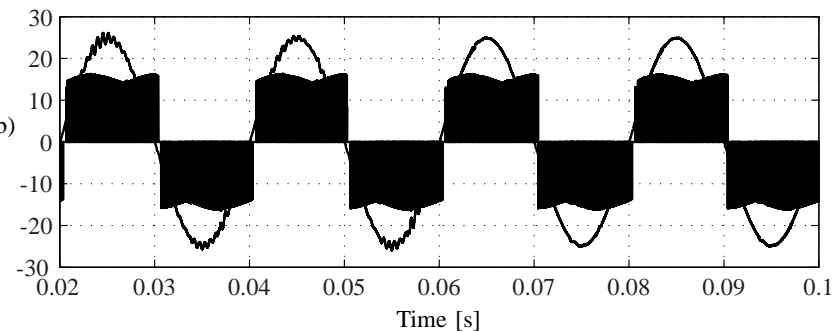

Fig. 10. Simulation results of the proposed IMPC; before $t=0.06$ [s] without active damping, after $t=0.06[\mathrm{~s}$ ] with active damping: (a) source voltage $v_{s A}[\mathrm{~V} / 10]$ and source current $i_{s A}[\mathrm{~A}]$; (b) capacitor voltage $v_{A}[\mathrm{~V} / 10]$ and input current $i_{A}[\mathrm{~A}]$.

(a)
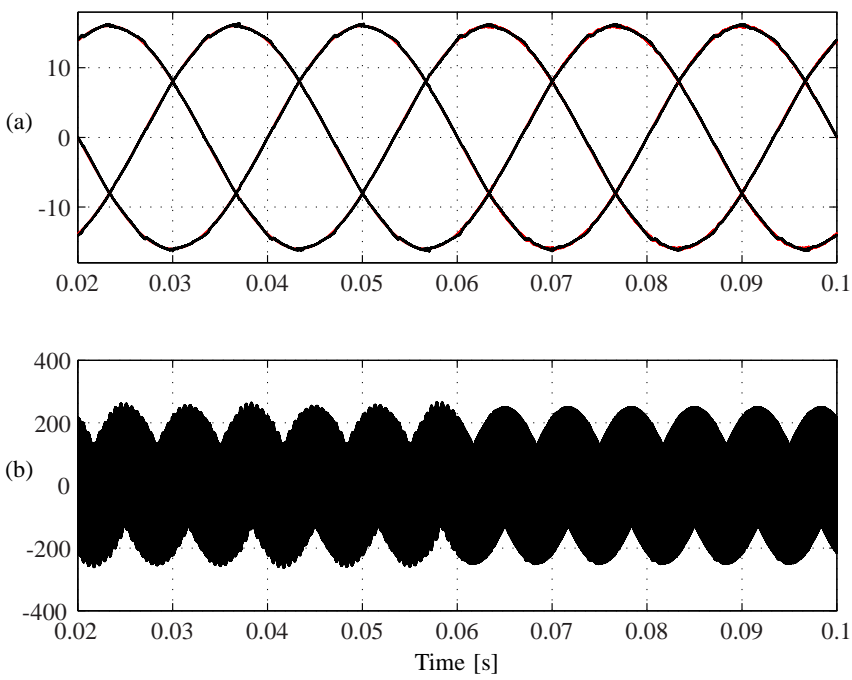

Fig. 11. Simulation results of the proposed IMPC; before $t=0.06$ [s] without active damping, after $t=0.06$ [s] with active damping: (a) load currents $\mathbf{i}_{\mathbf{o}}$ [A] and its respective references $\mathbf{i}_{\mathbf{o}}{ }^{*}[\mathrm{~A}]$; (b) load voltage $v_{a}[\mathrm{~V}]$.

After the implementation of active damping, the source current $i_{s A}$ is improved and the THD is reduced to $10.62 \%$. In Fig. 8 is also evident the effect of the input filter which mitigates the high harmonic components of the input currents due to the commutations. Fig. 9(a) shows the load currents $\mathbf{i}_{\mathbf{o}}$ which track very well their respective references $\mathbf{i}_{\mathbf{o}}{ }^{*}$ which is established as 16[A]@25Hz. Before the active damping implementation, the THD is equal to $1.06 \%$ and later this is slightly incremented to $1.57 \%$. Fig. 10 and Fig. 11 show results for the proposed IMPC technique in the DMC with and without active damping implementation. It is evident the effect of the operation at fixed switching frequency because a better performance of the full system is observed. 
As shown in Fig. 10(a), despite of the operation at fixed switching frequency, there is still an oscillation in the source current with a THD of $13.71 \%$ which is reduced to $4.30 \%$ with the active damping technique. This effect is also observed in Fig. 10(b) where the capacitor voltage $v_{A}$ presents a better sinusoidal waveform in comparison to the classical MPC. Again, it is obtained a good performance of the input filter because the high order harmonics produced by the commutation of the switches are eliminated. Fig. 11 show the results on the load side of the DMC where is observed a very good tracking of the load currents $\mathbf{i}_{\mathbf{o}}$ to their respective references $\mathbf{i}_{\mathbf{o}}{ }^{*}$ with lower ripple in comparison to the classical MPC implementation. Before the implementation of active damping the THD of the load currents is equal to $0.84 \%$ and after that it is equal to $0.87 \%$.

\section{CONCLUSION}

In this paper has been presented an indirect model predictive current control strategy with minimization of the instantaneous reactive input power for a direct matrix converter operating at fixed switching frequency which has been enhanced with an active damping method to reduce the resonance of the input filter. The method uses the idea of fictitious $d c$-link in order to separate the control of both input and output stages of the converter. By doing this, it is possible to reduce the complexity of the control, the operation at fixed switching frequency but also avoid the calculation of a suitable weighting factor for the control of both instantaneous reactive input power and load currents variables. By considering the proposed strategy, a new alternative has emerged for the control of both the input and load currents in a direct matrix converter.

\section{ACKNOWLEDGMENTS}

The authors would like to thank the financial support of Programa en Energías CONICYT - Ministerio de Energía ENER20160014 and FONDECYT Regular 1160690 Research Project.

\section{REFERENCES}

[1] L. Empringham, J. Kolar, J. Rodriguez, P. Wheeler, and J. Clare, "Technological issues and industrial application of matrix converters: A review," Industrial Electronics, IEEE Transactions on, vol. 60, no. 10, pp. 4260-4271, Oct 2013.

[2] J. Rodriguez, M. Rivera, J. Kolar, and P. Wheeler, "A review of control and modulation methods for matrix converters," Industrial Electronics, IEEE Transactions on, vol. 59, no. 1, pp. 58-70, Jan 2012.

[3] S. A. Davari, D. A. Khaburi, and R. Kennel, "An improved fcs-mpc algorithm for an induction motor with an imposed optimized weighting factor," IEEE Transactions on Power Electronics, vol. 27, no. 3, pp. 1540-1551, March 2012.

[4] C. A. Rojas, J. Rodriguez, F. Villarroel, J. R. Espinoza, C. A. Silva, and M. Trincado, "Predictive torque and flux control without weighting factors," IEEE Transactions on Industrial Electronics, vol. 60, no. 2, pp. 681-690, Feb 2013.
[5] M. Uddin, S. Mekhilef, M. Rivera, and J. Rodriguez, "Predictive indirect matrix converter fed torque ripple minimization with weighting factor optimization," in 2014 International Power Electronics Conference (IPEC-Hiroshima 2014 - ECCE ASIA), May 2014, pp. 3574-3581.

[6] Y. Zhang and H. Yang, "Two-vector-based model predictive torque control without weighting factors for induction motor drives," IEEE Transactions on Power Electronics, vol. 31, no. 2, pp. 1381-1390, Feb 2016.

[7] V. P. Muddineni, A. K. Bonala, and S. R. Sandepudi, "Enhanced weighting factor selection for predictive torque control of induction motor drive based on vikor method," IET Electric Power Applications, vol. 10, no. 9, pp. 877-888, 2016.

[8] L. Tarisciotti, A. Formentini, A. Gaeta, M. Degano, P. Zanchetta, R. Rabbeni, and M. Pucci, "Model predictive control for shunt active filters with fixed switching frequency," IEEE Transactions on Industry Applications, vol. 53, no. 1, pp. 296-304, Jan 2017.

[9] S. A. Odhano, A. Formentini, P. Zanchetta, R. Bojoi, and A. Tenconi, "Finite control set and modulated model predictive flux and current control for induction motor drives," in IECON 2016 - 42nd Annual Conference of the IEEE Industrial Electronics Society, Oct 2016, pp. 2796-2801.

[10] H. Huisman, M. Roes, and E. Lomonova, "Continuous control set space vector modulation for the $3 \times 3$ direct matrix converter," in 2016 18th European Conference on Power Electronics and Applications (EPE'16 ECCE Europe), Sept 2016, pp. 1-10.

[11] J. Lei, B. Zhou, J. Wei, J. Bian, Y. Zhu, J. Yu, and Y. Yang, "Predictive power control of matrix converter with active damping function," IEEE Transactions on Industrial Electronics, vol. 63, no. 7, pp. 4550-4559, July 2016.

[12] M. Rivera, J. Rodriguez, B. Wu, J. Espinoza, and C. Rojas, "Current control for an indirect matrix converter with filter resonance mitigation," Industrial Electronics, IEEE Transactions on, vol. 59, no. 1, pp. 71-79, Jan 2012.

[13] M. Rivera, C. Rojas, J. Rodridguez, P. Wheeler, B. Wu, and J. Espinoza, "Predictive current control with input filter resonance mitigation for a direct matrix converter," Power Electronics, IEEE Transactions on, vol. 26, no. 10, pp. $2794-2803$, oct. 2011.

[14] J. Rodriguez, "A new control technique for ac-ac converters," IFAC Control in Power Electronics and Electrical Drives, Lausanne Switzerland, pp. 203-208, 1983.

[15] P. Wheeler, J. Rodriguez, J. Clare, L. Empringham, and A. Weinstein, "Matrix converters: a technology review," Industrial Electronics, IEEE Transactions on, vol. 49, no. 2, pp. 276-288, Apr 2002.

[16] M. Vijayagopal, L. Empringham, L. de Lillo, L. Tarisciotti, P. Zanchetta, and P. Wheeler, "Control of a direct matrix converter induction motor drive with modulated model predictive control," in 2015 IEEE Energy Conversion Congress and Exposition (ECCE), Sept 2015, pp. 43154321.

[17] — - "Current control and reactive power minimization of a direct matrix converter induction motor drive with modulated model predictive control," in 2015 IEEE International Symposium on Predictive Control of Electrical Drives and Power Electronics (PRECEDE), Oct 2015, pp. 103-108.

[18] C. F. Garcia, M. E. Rivera, J. R. Rodríguez, P. W. Wheeler, and R. S. Peña, "Predictive current control with instantaneous reactive power minimization for a four-leg indirect matrix converter," IEEE Transactions on Industrial Electronics, vol. 64, no. 2, pp. 922-929, Feb 2017.

[19] S. Vazquez, A. Marquez, R. Aguilera, D. Quevedo, J. Leon, and L. Franquelo, "Predictive optimal switching sequence direct power control for grid connected power converters," Industrial Electronics, IEEE Transactions on, vol. PP, no. 99, pp. 1-1, 2014. 